ISSN: 0514-7336 — ISSN electrónico: 2386-3943

DOI: https://doi.org/10.14201/zephyrus202085229242

\title{
NUEVA HIPÓTESIS EN TORNO A LA PRESENCIA DE ÉLITES LOCALES DE BARCINO EN LA PRODUCCIÓN DEL VINO LAYETANO: EL CASO DE LUCIUS MINICIUS NATALIS
}

\section{A new hypothesis on the presence of local elites from Barcino in Laietanian wine production: the case of Lucius Minicius Natalis}

\author{
Ramón Járrega Domínguez y Enric Colom Mendoza \\ Institut Català d'Arqueologia Clàssica (ICAC). Plaça Rovellat, s/n. 43003 Tarragona. Correo-e: rjarrega@icac.cat; \\ ecolom@icac.cat.ID ORCID: https://orcid.org/0000-0002-5250-2841; https://orcid.org/0000-0002-0969-9327
}

Recepción: 18/09/2019; Revisión: 24/02/2020; Aceptación: 23/03/2020

Resumen: Este trabajo pretende dilucidar el papel que desarrollaron algunos miembros de las élites romanas en la producción y distribución del vino producido en la Provincia Hispania Citerior. Planteamos la interpretación del sello $L \cdot M \cdot N$ y $L \cdot M \cdot N O$, documentados en ánforas layetanas de la forma Dressel 2-4, en relación con un Lucius Minicius Natalis que, dada la cronología de estos contenedores -c. 30-40 d. C.--, debió de ser un pariente y, probablemente, un antepasado directo de los dos cónsules barcinonenses que llevaron este nombre y desempeñaron su carrera en tiempos de Trajano y Adriano. Para establecer dicha hipótesis hemos llevado a cabo una extensa revisión de las evidencias epigráficas sobre contenedores anfóricos, así como el estudio prosopográfico de la gens Minicia y de los fundi que controlarían en el ager de Barcino. A partir de dichos análisis, concluimos que la opción más plausible es entender estas cartelas epigráficas sobre ánfora como marcas de Lucius Minicius Natalis y Lucius Minicius Natalis Opus u Officina, respectivamente. Por ello, la evidencia epigráfica nos permite sugerir que la fortuna de los conocidos Minicii Natales del s. II d. C., que llegaron a desarrollar una carrera consular, pudo tener su origen en la explotación vitivinícola de sus antepasados en el ager de Barcino.

Palabras clave: Laietania; ánforas; epigrafía; instrumentum domesticum; redes comerciales.

АвSTRACT: This paper intends to clarify the role played by the Roman elites in the production and distribution of wine produced in the Provincia Hispania Citerior. We propose the interpretation of stamps $L \cdot M \cdot N$, and $L \cdot M \cdot N O$, documented in Dressel 2-4 Laietanian amphorae, in relation to a Lucius Minicius Natalis. Given the chronology of these vessels $-c$. AD 30-40- this individual might have been a direct ancestor of the consuls from Barcino who bore this name and whose cursus honorum underwent during the time of emperors Trajan and Hadrian. To raise this hypothesis we have carried out an extensive review of the epigraphic evidence on amphorae, as well as the prosopographical study of the gens Minicia and fundi that would control the ager of Barcino. After such an analysis, we conclude that the most plausible option is to understand these epigraphic stamps on amphora as Lucius Minicius Natalis and Lucius Minicius Natalis Opus or Officina, respectively. Therefore, this interpretation of the epigraphic evidence allows us to conclude that most probably, the richness of the well-known Minicii Natales, who developed a consular career, must have had its origin in the wine production of their ancestors in the ager of Barcino.

Key words: Laietania; amphorae; epigraphy; instrumentum domesticum; trade networks. 


\section{Introducción ${ }^{1}$. La evidencia epigráfica}

En este estudio planteamos la posibilidad de identificación de unos sellos, documentados en posición in pede en ánforas layetanas de la forma Dressel 2-4 halladas en Carthago (Delattre, 1906: 43, n. ${ }^{\circ}$ 19; Freed, 1998: 355, fig. 2, n. ${ }^{\circ} 7$ ) y en la costa oriental de Mallorca (Colom y Járrega, 2020). Nos parece plausible que puedan asociarse a una familia de gran importancia de la Barcino romana -actual Barcelona-, como argumentaremos seguidamente.

Las referencias de Plinio (Nat. Hist. XIv, 71), Marcial (Epig., I, 26.9; vII, 53.6 y XIII, 118), Silio Itálico (Punica III, 369-370; xv, 177) y Floro (P. Anni Flori Vergilius orator an poeta $)^{2}$ recogidas y valoradas por Miró (1985) apenas aportan datos sobre los vinos layetanos y tarraconenses, por lo que es necesario acudir a la arqueología. En la costa catalana las figlinae donde se produjeron ánforas son muy abundantes (Miró, 1988b; Revilla, 1995; Tremoleda, 2000 y 2008), pero en la mayoría de ellas no se han llevado a cabo excavaciones sistemáticas en las mismas.

El estudio de los sellos que encontramos en las ánforas, en el borde, el cuello y, especialmente, en la base, constituye un elemento de juicio de gran interés para el estudio de los personajes involucrados en el proceso de producción de estas ánforas. En este sentido, podemos mencionar los estudios de diversos investigadores (Miró, 1988a; Pascual, 1991; Revilla, 1995 y 2004; Comas, 1997; Carreras y Guitart, 2009; Berni, 2010 y 2015; Carreras et al., 2013; Járrega, 2015, 2016a, 2016b, 2018; Carreras et al., 2019), que han permitido arrojar luz sobre estos temas.

En un trabajo reciente (Járrega, 2018) hemos recogido las evidencias que conocíamos hasta ahora a nomina mencionados en sellos de ánforas de la forma Dressel 2-3 o Dressel 2-4 del nordeste de la

1 Este trabajo se ha llevado a cabo en el marco del proyecto de I + D 'Figlinae hispanae (FIGHISP). Catálogo en red de las alfarerías hispanorromanas y estudio de la comercialización de sus productos' (PGC2018-099843-B-I00).

2 Consultadas a partir de las FHA.
Hispania Citerior ${ }^{3}$, con la intención de intentar comprobar a quiénes pudieron atribuirse estos sellos, y si estos pueden asociarse o no a las élites urbanas, como propone Revilla (2002). Desgraciadamente, los resultados del dicho estudio no son concluyentes, puesto que, a diferencia de las ánforas de las formas Tarraconense 1, Oberaden 74 y Pascual 1, que también hemos estudiado en este sentido (Járrega, 2015, 2016a y 2016b), en las Dressel 2-4 las referencias a nomina son muy escasas, y quedan en numerosas ocasiones reducidas a simples iniciales, como en el caso que nos ocupa. También podemos considerar, en paralelo al caso de las ánforas, la presencia de nomina en sellos de dolia y en tégulas, poco abundantes pero que han proporcionado ejemplos significativos, como, por citar un par de casos, el Publius Usulenus Veiento que marcó su nombre en ánforas y tégulas en el taller de Llafranc, en el término municipal de Palafrugell (Christol y Plana, 1997, 1998), o el Caius Iulius Laetus documentado en la figlina de Ermedàs, en el término de Cornellà del Terri (Tremoleda, 2016), ambos en las comarcas gerundenses. Probablemente la presencia de estos nomina en este tipo de soportes es equiparable al caso de las ánforas, y la explicación más lógica es que en todos estos casos se alude al propietario de la figlina.

Los sellos objeto de nuestro estudio están enmarcados en cartela circular, lo cual dificulta su lectura. Sin embargo, se trata claramente de iniciales de tria nomina, como lo indican las interpunciones existentes entre las letras. Por ello, podrían leerse $M \cdot N \cdot L$-en cuyo caso el praenomen tendría que ser Marcus, dado que es uno de los praenomina más frecuentes en la Hispania romana-, pudiéndose desarrollar eventualmente como $M$ (arcus)

3 Si bien, en el sentido estricto, podemos hablar de la forma Dressel 2-3, ya que estas formas se produjeron en la Hispania Citerior o Tarraconensis, como proponen López Mullor y Martín Menéndez (2008a y 2008b), la denominación, que ya es tradicional, de Dressel 2-4, propuesta por Tchernia y Zevi (1972), nos sigue pareciendo adecuada al referirse a una 'familia' anfórica, a pesar de que la forma Dressel 4 es, por lo que sabemos, una producción estrictamente itálica. Por ello, usaremos aquí la denominación Dressel 2-4. 


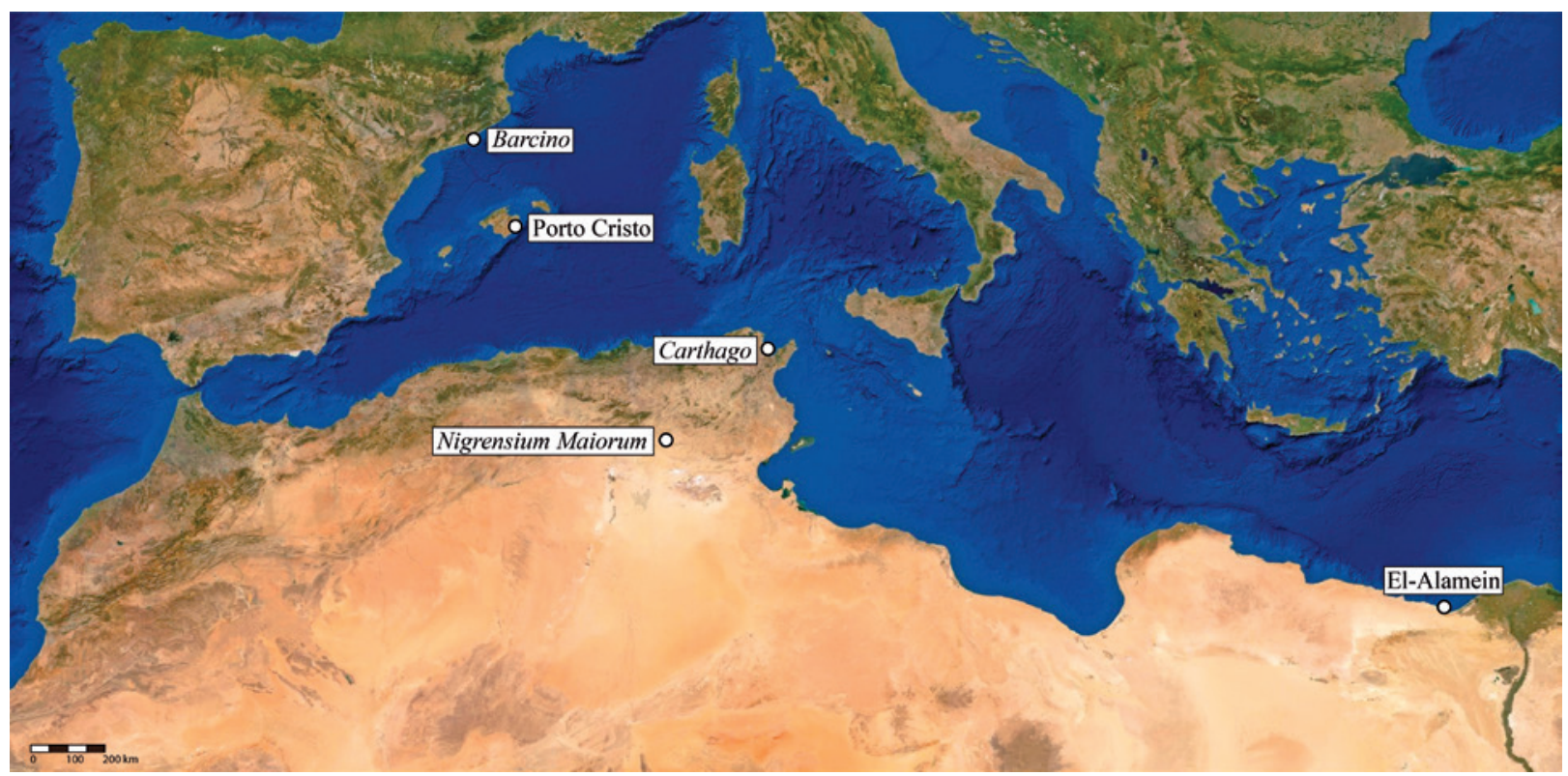

FIG. 1. Lugares donde se han documentado marcas epigráficas en instrumentum domesticum relacionadas con los Minicii Natales, asi como su ciudad de origen.

$N$ (onius) L(aetus), M(arcus) $N$ (aevius) L(onginus) etc., o $N \cdot L \cdot M$-bastante improbable, pues el praenomen debería ser Numerius, que era absolutamente minoritario-. Por ello, creemos que la lectura más fiable es $L \cdot M \cdot N$, leída en sentido contrario al de las agujas del reloj, tal y como ya propuso en su momento Freed (1998: 353), máxime teniendo en cuenta la existencia de otra variante de esta marca. Nos referimos a la estampilla $L M N O$, en este caso sin interpunciones aunque también aparece en cartela circular, en el llamado "segundo muro de ánforas de Carthago" (Delattre, 1906: 43, n. ${ }^{\circ}$ 18; Freed, 1998: 355, fig. 2 , n. ${ }^{o} 8$ ), en la cual creemos que la letra 'o' puede desarrollarse como officina. Además, Lucius es el praenomen más corriente en Hispania (Abascal, 1994: 28). Cabe destacar que, años antes, esta marca fue publicada por Pascual (1991: 90, n. ${ }^{\circ}$ 140) como $M N O L$, si bien pensamos que la lectura que hizo es incorrecta.

Se conoce otro ejemplar, semicompleto -faltan solamente el cuello, las asas y el borde-, que corresponde claramente a una Dressel 2, hallado en Marina El-Alamein, localidad situada en la costa egipcia, cerca de Alejandría. Si bien se ha publicado como un ánfora de Campania (Medeksza et al., 2008: 79, fig. 11), a juzgar por la fotografía, y más aun considerando el sello -que aparece en la parte superior del pivote-, podemos asegurar que se trata de una producción layetana. La marca -de la que se ofrece una detallada fotografía- presenta, en cartela circular, las letras $L \cdot M \cdot N O$, o bien $O L \cdot M \cdot N$. Nótese la presencia de interpunciones -a diferencia del ejemplar de Carthago- entre las letras $L, M$ y $N$, que son claramente las iniciales de unos tria nomina, por lo que la letra o queda de algún modo aislada, ganando peso la posibilidad de que pueda interpretarse como la inicial de officina $-\mathrm{o}$ tal vez opus-; más improbable nos parece que corresponda a una segunda letra del cognomen. Esta abreviatura se encuentra también, en cartela rectangular, en algunas marcas de ánforas layetanas de la forma Pascual 1. Concretamente, podemos citar a título de ejemplo la marca $O \cdot I V L I \cdot A N T E R$; aunque erróneamente se ha considerado la primera letra como una $\mathrm{Q}$, que correspondería al praenomen Quintus, se conoce también la variante $C \cdot I V L I \cdot A N T E R$ (Járrega, 2016a: 166), así como el caso del sello o IVLI·THEOPHIL (Bergé, 1990: 153, n. o 81; Bouscaras, 
1974: 110), variante de la abundantemente documentada IVLI·THEOPHIL, cuya letra 'o' también fue transcrita como $O$ (fficina) u $O$ (pus) (Berni y Miró, 2013: 72).

Como hemos avanzado con anterioridad, la marca $L \cdot M \cdot N$ ha sido documentada recientemente en el fondo marino de Porto Cristo (Mallorca, Islas Baleares) y publicada en un trabajo nuestro (Colom y Járrega, 2020). Aparece impresa sobre un

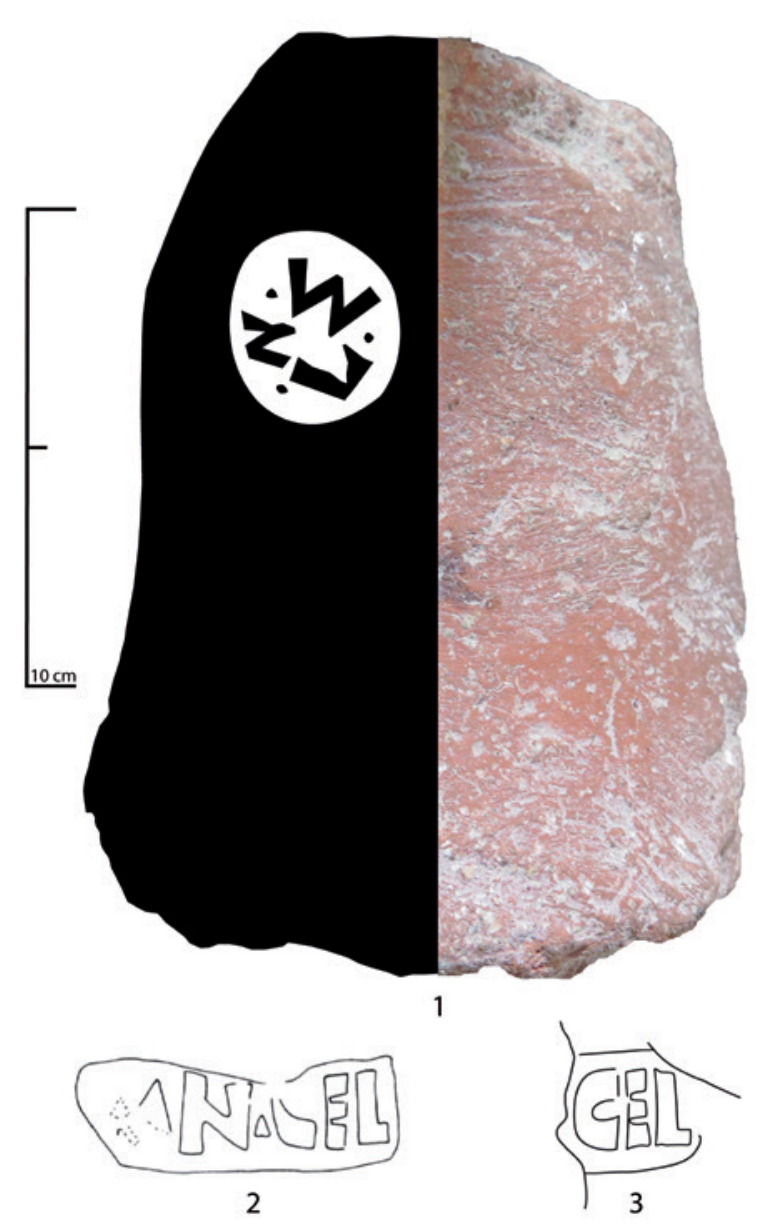

FIG. 2. Marcas sobre distintos materiales: 1) pivote recuperado en el fondo subacuático de Porto Cristo (Manacor, Mallorca); 2) fragmento de ánfora Dressel 2-4 con marca MIN.CEL, in collo, recuperada en la villa romana de la Torre del Cap del Pont, Vic (según Berni, 1996: 317, n. ${ }^{\circ}$ 7); 3) la misma marca, aunque fragmentada, procedente de les Begudes, Sant Joan Despi (según Berni y Carreras, 2013: 210, n. ${ }^{\circ} 78 a$ ). fragmento de pivote de gran tamaño de la forma Dressel 2, con una pasta cerámica de color rojo-anaranjado, claramente típica del área layetana, aunque muestra un aspecto más depurado de lo habitual (Fig. 2, n. ${ }^{\mathrm{o}}$ 1).

\section{Las élites urbanas y su posible reflejo en los sellos anfóricos}

Ciertamente, la sola mención de las tres iniciales de los tria nomina nos impide identificar con seguridad el personaje, pero creemos que resulta interesante presentar una hipótesis explicativa. Se conocen otros casos en los que, también a nivel hipotético, se ha planteado una identificación de personajes, o familias, de las élites urbanas, a partir de sellos con las iniciales de los tria nomina.

En el ager de Tarraco -Tarragona- se ha documentado el sello $L \cdot C \cdot M$ en la alfarería de Mas d'en Corts (Berni, 2010: 175-176, n.o 137; Járrega y Prevosti, 2011: 480-481), fechado en el s. I d. C. Se ha propuesto relacionarlo con el hallazgo en la misma zona del sello $M \cdot C L O \cdot M A$, del que se conoce un ejemplar sobre dolium de la figlina de Mas de Gomandí, así como probablemente otro en la villa romana de Mas d'en Toda (Riudoms) (Berni, 2010: 204-205, n.os 169 y 170), que aludía a un Marcus Clodius Martialis. Este personaje es conocido por una inscripción hallada en Tarragona (Alföldy, 1975: n. ${ }^{\circ} 168$ ), en la que se indica que fue praefectus Balearum; al parecer, puede datarse hacia la época flavia, o inicios del s. II. Por ello, entra dentro de lo posible que estuviese emparentado -quizás fuera un descendiente directo- con un hipotético Lucius Clodius Martialis, al que podría hacer referencia la marca con las iniciales $L \cdot C \cdot M$.

Por otra parte, conviene recordar la aparente existencia de un sello con la posible lectura $M C[L O ?] M[A ?]$, sobre ánfora de la forma Dressel 2-4, de la figlina de Mas d'en Corts (Berni, 2010: 176-177, n. 138), aunque no es posible comprobarlo porque el ejemplar, al parecer, se ha extraviado; en este caso, podría relacionarse con el mismo Marcus Clodius Martialis o con un pariente homónimo. 
Con ello, parece que nos podemos hallar frente a una familia perteneciente a la élite de Tarraco, que probablemente tenía un amplio fundus en la actual comarca del Baix Camp, en el término municipal de Riudoms, centrado en el mencionado Mas d'en Toda (Cabrelles, 2013), y en el que se producía vino, posteriormente envasado en ánforas de la forma Dressel 2-4 (Járrega y Prevosti, 2011: 480-481). No es una identificación concluyente, pero creemos que resulta bastante probable.

Otro caso estudiado recientemente (Járrega, 2018: 192-194) es el del sello $L \cdot M \cdot O$, abundantemente documentado en la figlina de Can Viader (Malgrat de Mar, Barcelona), en pivotes de la forma Dressel 2 correspondientes a la última fase de la producción, en época de Nerón o Vespasiano (Járrega y Berni, 2013). Este sello lo podemos asociar de forma hipotética a Lucius Marcius Optatus, conocido por una inscripción de Iluro, la actual Mataró (Fabre et al., 1983: 35-42, n. ${ }^{\circ}$ 5; 1984: 147-150, n. ${ }^{\circ}$ 101). Se trata de un personaje de la élite iluronense, natural de Tarraco, que fue duunviro quinquenal en Iluro, desarrolló después una carrera militar y falleció - desconocemos la causa- en Frigia. Esta inscripción plantea problemas de datación, centrados en el sentido que se pueda dar a la expresión "duunviro quinquenal". Se ha planteado que puede corresponder al momento inicial del municipium de Iluro, en época de Augusto, o bien a época flavia, a partir de la carrera militar del personaje. Si bien la primera opción es la que parece tener más predicamento (Rodà, 2010: 187), no podemos descartar la relación entre el personaje mencionado en la inscripción y los sellos anfóricos. En el caso de que la inscripción fuese de época augústea, podría corresponder a un antepasado del mencionado en los sellos; y si es de época flavia, podría ser él mismo. En todo caso, como en el de los Clodii Martiales de Tarraco, creemos que la hipótesis es factible, máxime si tenemos una perfecta conjunción entre las iniciales de los tria nomina mencionados en los sellos anfóricos de la figlina de Malgrat y la inscripción iluronense de Lucius Marcius Optatus, así como su coincidencia en una misma área geográfica, pues Malgrat de Mar se encuentra cerca de Mataró, quizás en su mismo territorium en época romana.
Rigiéndonos por el mismo sistema, vamos a intentar plantear una hipótesis explicativa sobre el personaje que puede estar tras los sellos aquí estudiados, siempre que el orden correcto de lectura sea $L \cdot M \cdot N$. Como hemos dicho, el sello se conoce solamente en las áreas de exportación o in transito, puesto que se ha documentado en un hallazgo submarino de Porto Cristo, en Mallorca, quizás correspondiente a un pecio, o más probablemente en contexto de fondeadero-que obviamente, como hallazgo aislado, no podemos datar- y en el denominado 'Segundo Muro de Ánforas' de Carthago. Este último sí que ha podido fecharse, por las dataciones consulares de dos tituli picti, en época de Tiberio y Calígula (Delattre, 1906).

Hasta el hallazgo de Porto Cristo no nos ha sido posible precisar si el sello $L \cdot M \cdot N$ corresponde o no a la producción que, de un modo equívoco, Tchernia (1971) propuso denominar 'tarraconense', haciendo referencia a la provincia romana, cuyo nombre oficial, documentado por la epigrafía, seguía siendo en el Alto Imperio Provincia Hispania Citerior. En este caso, si bien desconocemos la figlina de origen, podemos afirmar, a partir del análisis macroscópico, que corresponde a una producción de la antigua Laietania o Leetania, situada en la zona central de la actual Cataluña, básicamente en el área costera de la provincia de Barcelona. Este dato acota bastante la zona originaria de estas ánforas y, por lo tanto, nos permite intentar identificar al personaje mencionado en relación con los que conocemos en la epigrafía de la zona.

\section{Los Minicii Natales de Barcino}

A través de la epigrafía lapidaria conocemos dos personajes, Lucius Minicius Natalis y su hijo, Lucius Minicius Natalis Quadronius Verus, que formaron parte de la élite más encumbrada de la colonia Barcino-Barcelona-y del mismo Imperio romano, llegando ambos a ser senadores y cónsules. Gracias a varias inscripciones encontradas en diversos puntos del Imperio (CIL VIII, 4643; CIL XI, 2925; CIL XI, 3002; CIL XIV, 3554; CIL XIV, 3599) se conoce la 
amplia carrera pública de estos personajes ${ }^{4}$. Además de otras magistraturas -que componen un largo cursus honorum-, podemos destacar que el padre fue cónsul sufecto en el 106 y el hijo en 139; ambos fueron también procónsules de África, el primero en los años 121-122 y el segundo hacia los años 153-154 (Rodà, 1988: 49; Caballos, 1995: 221-224; Fabre et al., 1997: 92 y 95). Ambos son mencionados en una inscripción monumental (CIL II, 4510; IRC IV, 30) que conmemoraba la construcción, en el 125, a expensas suyas, de unas termas públicas en Barcino. Estas fueron edificadas en terreno de su propiedad, y se identifican con las documentadas en la plaza de Sant Miquel de Barcelona, en las cercanías del foro romano. Se conoce también el testamento del hijo (CIL II, 4511; IRC 33), en el que legó a los barcinonenses la suma de cien mil sestercios.

En 1878 fue descubierta una inscripción en Olimpia ${ }^{5}$, que conmemoraba que Minicius Natalis iunior ganó una carrera de cuadrigas en el estadio de dicha ciudad, con ocasión de la 227. ${ }^{\text {a O Olimpía- }}$ da, en el año 129 (Verrié, 1989). Evidentemente, se considera de forma unánime que Minicius Natalis era el propietario de los caballos y de la cuadriga, no el auriga.

Como se ha indicado, tanto el padre como el hijo fueron procónsules de la provincia de África. Precisamente, el hallazgo de un pedestal (IRC 34) que se ha propuesto fechar hacia el 125 y que, aunque de texto fragmentario, se ha sugerido que fue dedicado a Lucius Minicius Natalis iunior (Rodà, 1978; Fabre et al., 1997: 98; Eck y Navarro, 1998; Erkelenz, 1998) testimonia una dedicación de la Colonia Iulia Carthago al mismo en las termas o en el foro de Barcino. También sabemos que él mismo fue patronus de la ciudad de Leptis Magna (IRT 536: 297-298; Caballos, 1995: 221-222). Este hecho nos indica la relación entre los Minicii y la provincia de África, que debe asociarse con sus respectivos proconsulados en la misma.

4 Un resumen reciente, con bibliografía actualizada, del cursus honorum de ambos se encuentra en Abascal, 2016: 183-184.

5 Una copia de esta inscripción se encuentra en Barcelona, frente al Consejo Superior de Deportes.
Por otro lado, se conoce una tégula procedente de la colección de antigüedades del barón de Fargione, en Sicilia, que presentaba un sello con el texto CEL[LA?] (hedera) NIGR MAIO[RVM] / L $\cdot M I N I-$ CI.NATALI[S] / EVLALVS ACTOR E[IVS] (CIL VIII 10962; CIL XV 8045, 12). La inscripción hace referencia a un Lucius Minicius Natalis y a cierto $E u$ lalus, definido como actor eius, lo que se ha interpretado como referente a la existencia de un fundus. El texto $N I G R \cdot M A I O[R V M]$ se ha asociado al oasis de Nigrensium Maiorum, actualmente Negrine, Argelia. Dado que en Ad Maiores -actualmente Henchir Besseriani-, muy cercano a este oasis, se construyó un fuerte por parte de Lucius Minicius Natalis padre-como consta por las inscripciones que mandó erigir en las puertas del mismo-, cuando fue legado propretor en los años 104-105, la tégula debe hacer referencia a un fundus de este personaje situado en dicho lugar, posiblemente destinado al cultivo de aceite (Cortadella, 2006: 208-209), si bien algunos autores, a raíz de nuevas e interesantes interpretaciones de este texto, se muestran más cautos en este aspecto (Mayer, 2015: 1518).

Aunque directamente no conocemos más miembros de esta familia, la epigrafía de Barcino nos ha permitido documentar un sevir augustal llamado Pedanius Clemens (IRC, 105, 107, 108, 114, 123), ligado -sin duda por vía de la manumisión- con la importante familia barcinonense de los Pedanii. Un pariente -tal vez un hijo adoptivo- de Pedanius Clemens se llamaba Clemens Minicianus, lo que permite establecer una posible relación entre las dos importantes familias Pedania y Minicia. De todos modos, cabe tener en cuenta que muchos individuos fueron libertos o descendientes de libertos y tomaron estos nomina a partir de su origen servil, como parece indicar el caso del mismo Pedanius Clemens (Olesti y Carreras, 2013: 185).

Tampoco hay que olvidar a Q. Licinius Silvanus Granianus, cónsul en el 106 -el mismo año que $M i$ nicius Natalis padre- y patrono de Baetulo -Badalona- (IRC I, 139), de donde pudo ser originario, y su hijo Quintus Licinius Silvanus Granianus Quadronius Proculus, tribuno de la sexta legión (IRC I, 138). El nomen Quadronius podría indicar alguna relación 
familiar entre este personaje y Minicius Natalis hijo (Syme, 1982-83: 247; Fabre et al., 1997: 95; Rodà, 2010: 185).

Olesti (2005: 180) propone una posible relación entre la gens Sempronia y los Minicii Natales, basándose en una inscripción barcinonense de cierto $L$. Sempronius Carpio (IRC IV, 32), en la que se indica que era cliente de L. Minicius Natalis Quadronius Verus; Olesti considera la posibilidad de que este Sempronius tuviese alguna relación familiar con la mansio Semproniana situada, al parecer, en el casco urbano de la actual Granollers (Estrada, 1998: 204), así como con la estampilla SEMPR, en ánforas de la forma Pascual 1 (Járrega, 2016b: 80-81). De todos modos, estas posibles relaciones son muy hipotéticas.

Finalmente, podemos citar otros cuatro Minicii mencionados en la epigrafía de Barcino: el sevir augustal Minicius Myron (IrC IV, 1), un Minicius Diadumenianus (IRC IV, 191), una Minicia Iucunda (IRC IV, 161) y un Minicius (IRC IV, 319) documentado por una inscripción funeraria conservada en estado fragmentario. Los dos primeros, de evidente origen servil a juzgar por su onomástica, son nombrados en inscripciones que pueden datarse en la primera mitad del s. II, por lo que se ha sugerido que pudieron haber sido libertos de los Minicii $\mathrm{Na}$ tales (Rodà, 2010: 185).

Fuera de Barcino, pero en su entorno geográfico, se conoce un L. Minicius Apronianus por dos inscripciones de Tarraco (CIL II, $4071=$ RIT, 23; CIL II, 4274/6072 = RIT, 0918) y una de Caldes de Montbui (Vallès Oriental, Barcelona), en la que consta que erigió un monumento a Apolo (IRC, I, 34). Apronianus fue duunviro quinquenal de $T a-$ rraco en el s. II, por lo que fue un miembro de la élite de la capital provincial. En la misma ciudad se conocen otros Minicii, concretamente L. Minicius Philargurus, probablemente de época republicana (RIT, 13); L. Minicius Rufus (RIt, 625), y su liberta y esposa, [Mi]ni[ci]a (RIT, 626), del s. I d. C.; $L$. Minicius Pudens (RIT, 376), de época de Adriano; L. Min[i]c[ius] Zoticus (RIT, 626), fechable a finales del s. II o inicios del III, así como L. Minicius Astragalus y Minicia Satulla (Andreu et al., 2006 y 2008), que vivieron a finales del s. I o inicios del in d. C.. Como se ha visto, la mayor parte de ellos eran libertos, y podrían haber tenido alguna relación con los Minicios de Barcino.

En Ampurias se documenta un Min(icius?) $\mathrm{Fe}$ li[x---] / [---] Itali[cus?---], datado en época republicana y de probable procedencia itálica (IRC III, 98), lo que indica que la gens Minicia ya estaba asentada en la Hispania Citerior antes del cambio de Era. Es muy posible que los Minicii de Barcino se instalasen en la ciudad desde la fundación de la misma en época de Augusto, lo que explicaría que pocos años después poseyesen un fundus donde se producía vino para su comercialización.

\section{La gens Minicia y las propiedades rurales en el ager Barcinonensis}

Existe un elemento que nos permite documentar la existencia de propiedades territoriales ligadas a la gens Minicia en el ager de Barcino. Mayer (1986: 23) propuso que el lugar de Miziano, mencionado por la documentación medieval -y que también aparece bajo las formas Miciano, Micano, Mitiano y Minciano-, y ubicable en la zona de Sant Joan Despí -cerca de la capilla de Sant Pere de Romaní-, sea una corrupción de Miniciano, con lo que podría corresponder a un fundus propiedad de los Minicii Natales (Fig. 3). Otros autores (Olesti, 2005: 181; Olesti y Carreras, 2013: 165) han considerado más prudente limitarse a situar en esa zona una propiedad de algún miembro de la gens Minicia; sin embargo, dada la importancia de dichos personajes dentro de la élite de Barcino, creemos que es bastante razonable relacionar el fundus con los dos miembros más famosos de la gens.

Los topónimos conservados en la documentación medieval nos han permitido conocer de forma indirecta la existencia de fundi en el ager de Barcino en época romana, los nombres de cuyos propietarios habrían quedado fosilizados en los textos medievales. Ello nos permite documentar el nombre de diversos fundi, como Cornelianus, Paullinianus, o Sempronianus (Berni et al., 2005; Olesti, 2005 y 


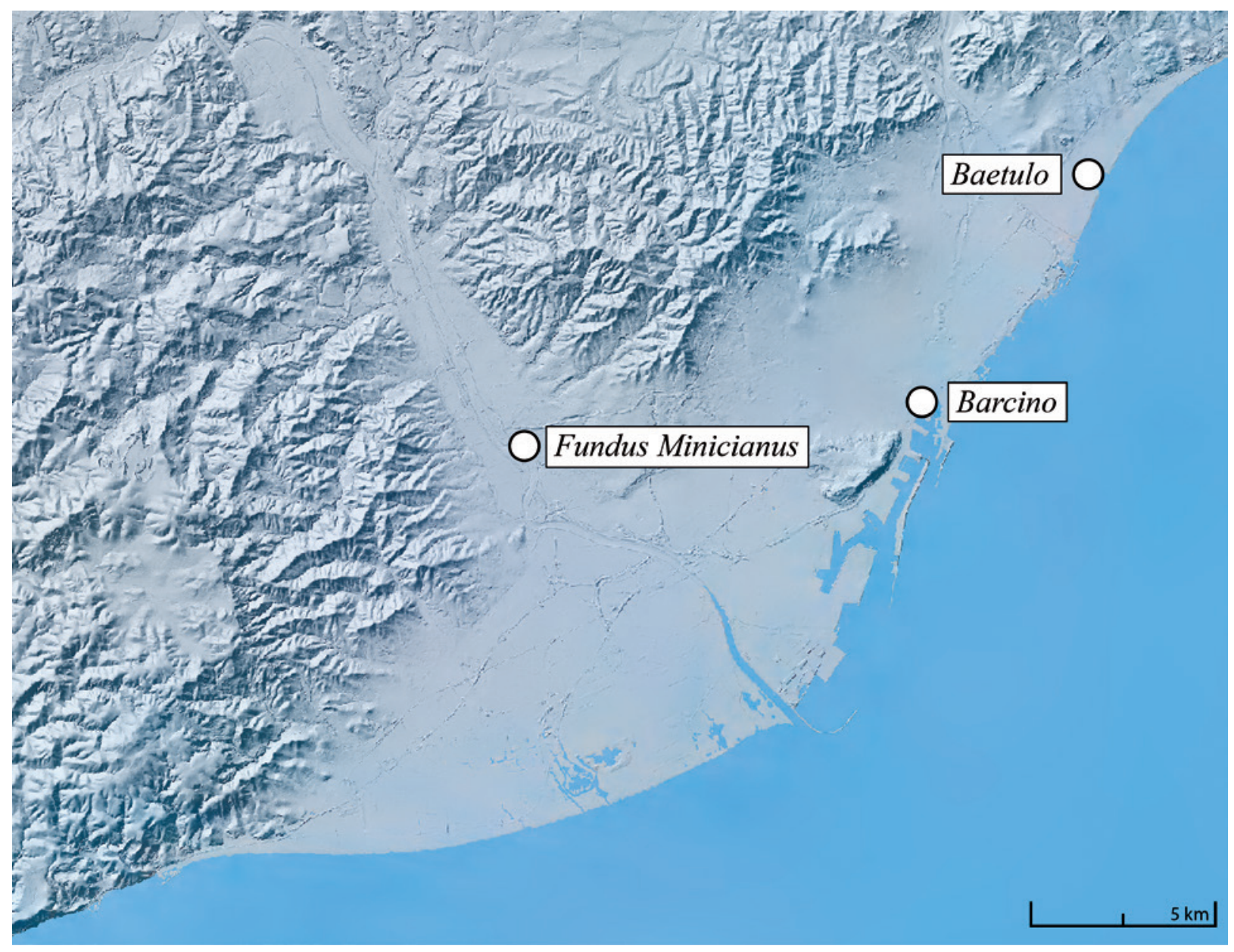

Fig. 3. Localización de Barcino y Baetulo asi como posible ubicación del fundus Minicianus (a partir de Digital Atlas of the Roman Empire [https://dare.ht.lu.se/]).

2008; Olesti y Carreras, 2013). Resulta interesante recalcar un caso, Lizano, que debe corresponder a un Licinianus, que evidentemente hace referencia a la gens Licinia, y que podría relacionarse con otro personaje de gran importancia en la administración imperial, contemporáneo de los Minicii Natales: Lucius Licinius Sura.

El topónimo Lizano, conservado en la documentación medieval y fosilizado en los actuales Lliçà de Munt i Lliçà de Vall -comarca del Vallès Oriental, provincia de Barcelona-, se ha sugerido que pudiese ser una propiedad de L. Licinius Sura, el conocido general de Trajano, o de su liberto L. Licinius Secundus (Mayer, 1996: 24) y que podía haber sido una importante propiedad vitivinícola desde antes de la época flavia. Mayer llega a sugerir que, así como los Minicii podían haber controlado la economía de la zona de la actual comarca del Baix Llobregat -y tal vez una parte del Vallès Occidental-, Licinius Sura podía haber dominado una buena parte del Vallès Oriental. Por otro lado, Berni, Carreras y Olesti (2005: 183) dudan de la identificación tradicional de Granollers con la mansio Semproniana -nombre que podría corresponder a un fundus-, y proponen considerarla como el centro del fundus Licinianus, relacionándola hipotéticamente con Licinius Sura.

Como en el caso de Minicianus, no podemos ir más allá de atribuir la propiedad del fundus $L i$ cinianus a algún miembro de la gens Licinia, pero, dada la importancia de Licinio Sura y de su liberto 
Licinius Secundus (cuya relación con Barcino está demostrada por la epigrafía), creemos que es probable que guarde relación con ambos o, al menos, con el segundo. Además, debemos recordar que el nomen Licinius es el sexto más abundante en Hispania, y es muy habitual en la antigua Layetania, estando documentados en la epigrafía de Barcino, Baetulo e Iluro (Berni et al., 2005). En relación con las ánforas, se conoce una marca LICIN en Pascual 1 (Járrega, 2016b: 79), así como T.LIC -aparentemente, en referencia a un Titus Licinius- en Dressel 2-4 (Járrega, 2018: 183-184), y un posible P.LIC en Oberaden 74 (Járrega, 2017). Si las identificaciones son correctas, nos encontramos con diversos Licinii relacionados con la producción anfórica, que no sabemos si podían o no estar emparentados entre sí.

Por otro lado, en el caso de Licinius Sura se ha de considerar la hipótesis de Dupré (1994) y Alföldy (1996), quienes por motivos estilísticos, arquitectónicos y epigráficos consideraron que el arco de Berà, cerca de Tarragona -que según consta en su inscripción fue erigido por orden de Lucius Licinius Sura-, no corresponde al general de Trajano, sino a un antepasado homónimo suyo de época augústea. La ausencia de titulaciones oficiales es, según Dupré, un indicio de que no se trata del personaje del s. II, sino de un ancestro suyo. Recordemos que ya Syme (1981: 276; 1982-83: 257) propuso una posible relación entre el $L$. Sura mencionado en las monedas de Celsa -en el término municipal de Velilla de Ebro, provincia de Zaragoza- y Licinius Sura, que podría descender de los colonos itálicos establecidos en dicha ciudad. Sin embargo, a pesar de llevar el mismo cognomen, la ausencia del nomen en las citadas monedas celsenses nos invita a ser prudentes. De todos modos, el hecho de que el Licinio Sura mencionado en el arco de Berà perteneciera a la tribu Sergia hace posible esta atribución, ya que Celsa estaba adscrita a la misma, mientras que $T a$ rraco corresponde a la Galeria.

Con todo ello, podemos pensar que la gens Licinia tuvo abundantes ramificaciones en el conventus Tarraconensis -al parecer, mucho más que la gens Minicia-, y que algunos de sus miembros, concretamente Licinius Sura y el anteriormente mencionado Licinius Silvanus Granianus, llegaron a las más altas magistraturas del Estado romano.

\section{Lucius Minicius Natalis, un posible productor de vino del s. I d. C.}

A partir de todos los paralelos y casos mencionados, proponemos aquí que el sello $L \cdot M \cdot N$ documentado en ánforas de la forma Dressel 2-4 en Porto Cristo -Manacor, Mallorca- y en Carthago pueda corresponder a un Lucius Minicius Natalis. Obviamente, si la cronología de las ánforas, a partir de los datos de Carthago, debe situarse en el segundo cuarto del s. I d. C., en época de Tiberio o Calígula, no puede tratarse de ninguno de los dos personajes consulares bien conocidos por la epigrafía lapidaria, que vivieron entre finales del s. I y el II, pero podría ser un antepasado suyo, tal vez el abuelo de Minicius Natalis padre. Creemos que los ejemplos de los Clodii Marciales y de los Licinii Sura, que permiten documentar una actividad vitivinícola y una herencia de padres a hijos dentro de la élite de Tarraco -y tal vez también de Barcino, en el caso de los Licinii-, nos autorizan a plantear esta actividad y esta continuidad para los Minicii Natales.

Por otro lado, como han puesto de relieve Olesti y Carreras (2013: 165), cabe destacar la existencia de la marca $M I N$ [icius].CEL[sius] (o CEl[sus]) en ánforas de la forma Dressel 2-4, que parece hacer referencia a un liberto de la gens Minicia. De esta marca se conocen dos ejemplares. El primero corresponde a un fragmento de ánfora de la forma Dressel 2-4, con el sello casi completo (Fig. 2, n. ${ }^{\circ}$ 2), hallado en la villa romana de la Torre del Cap del Pont (Daura y Puigví, 1982: 84), en las afueras de la antigua Auso (Vic, Barcelona); la marca, MIN.CELS, se documenta en el cuello (Berni, 1996: 316, n. ${ }^{\circ}$ 7; Berni y Carreras, 2013: 210, n. ${ }^{\circ} 78$; Berni, 2015: 62). Se trata de una pieza totalmente reconstruida, y se ha datado, por la cerámica de paredes finas que formaba parte del contexto (López Mullor, 1989), hacia los años 30-40 d. C.; es decir, la misma cronología que el ánfora de Carthago con la marca $L \cdot M \cdot N$. La 
segunda es una marca incompleta, restituible como [MIN].CEL, situada también en el cuello del ánfora (Fig. 2, n.o 3), que se halló en 2001 en unas excavaciones de urgencia de una villa romana en el paraje de Les Begudes, en el término de Sant Joan Despí -Barcelona-, y corresponde al mismo punzón que el ánfora hallada en Vic. En cuanto al nombre CEL, no sabemos si se trata del mismo personaje mencionado en la marca $C E L$, del taller de Can Tintorer (El Papiol; véase Berni y Carreras, 2013: 158-161, n. $\left.{ }^{\circ} 34\right)$, o de un homónimo.

En todo caso, nos parece enormemente significativo el hallazgo de la marca $M I N \cdot C E L$ precisamente en Sant Joan Despí, lo que refuerza la ubicación del fundus Minicianus en dicho lugar. Por ello, no sabemos si esta marca procedería de una alfarería cercana, como proponen Berni y Carreras, y que en tal caso cabría relacionar con los Minicii, o bien si en este mismo lugar existió alguna que no ha sido documentada todavía. Si el CEL mencionado en los sellos de la figlina de Can Tintorer-distante tan solo unos $8 \mathrm{~km}$ de Sant Joan Despí- fuese el mismo de la marca que nos ocupa, tal vez podríamos relacionar dicha alfarería con la actividad de los Minicii, si bien esta hipótesis es aventurada, ya que se ha documentado claramente la movilidad de los artesanos constatados en las marcas de las ánforas (Berni y Miró, 2013: 77-81).

Desafortunadamente, no podemos determinar la ubicación del centro productor de las ánforas con la marca $L \cdot M \cdot N$, pero, como ya hemos mencionado, por la observación macroscópica de su pasta corresponden, sin duda, a la antigua Laietania. Además, el caso de la marca $M I N \cdot C E L$ creemos que refuerza la identificación que hemos propuesto. Por ello, la existencia más que probable de un fundus de los Minicii en el área de Sant Joan Despí (Baix Llobregat) permite suponer que en el mismo se producía el vino que se envasaba en las ánforas que debieron de producirse en el mismo fundus o en sus proximidades. En esta zona se han documentado restos de al menos dos villas romanas, en la ermita de la Mare de Déu del Bon Viatge (Guasch et al., 1996: 43-45; Menéndez y Solias, 1996: 765-766), situada junto a la denominada vía Augusta, además de la antes mencionada de Les Begudes (Guasch et al., 1996: 45-47; Menéndez y Solias, 1996: 766), donde se halló el fragmento con la marca $M I N \cdot C E L$; ambos asentamientos, desgraciadamente, están aún por estudiar. Además, otra posible villa podría identificarse por algunos restos arquitectónicos documentados en la calle del Ferrocarril (Guasch et al., 1996: 43; Menéndez y Solías, 1996: 764-765).

Por otro lado, es reseñable el hecho de que Sant Joan Despí se encuentra situado enfrente -y al otro lado del río Llobregat- de la población actual de Sant Boi, lugar en el que se estableció un centro productor de ánforas y donde López Mullor (2009: 77) propuso que pudo haberse situado el punto de embarque marítimo de las ánforas que eran llevadas en barcazas desde los centros productores situados aguas arriba del río Rubricatus.

Como propone Cortadella (2006: 209), los senadores hispanos que destacaron en tiempos de Trajano y Nerva, y más concretamente los que aquí nos conciernen -los de la Hispania Citerior-, pudieron descender de los productores y exportadores del vino tarraconense, al que podemos añadir, en este caso, el layetano. La desaparición del comercio del vino layetano -que no del de Tarraco y el de la costa meridional de la Provincia Hispania Citerior-en época flavia, por causas que desconocemos, debió comportar sin duda un cambio en las inversiones económicas de las élites urbanas. La posterior presencia en Roma y en los altos cargos del imperio de los Minicii Natales, así como de otros personajes como Lucius Licinius Sura, permiten pensar que su riqueza se basó en otras fuentes económicas, tal vez en inversiones en la provincia de África, como sugiere Cortadella a partir de la implicación de los mencionados Minicii con dicha provincia, aunque algunos autores no están de acuerdo con esta versión (Laporte y Dupuis, 2009; Mayer, 2015).

Nos parece de un enorme interés el hallazgo de un ánfora layetana con el sello $L \cdot M \cdot N O$ en Egipto, ya que es la primera vez que se puede documentar un ejemplar de esta procedencia en el Mediterráneo oriental. Probablemente formaba parte de una corriente comercial hacia Egipto y la India, como lo demuestra el hallazgo de un asa de ánfora 
probablemente de la forma Dressel 2-4 y procedente del Maresme -a juzgar por las características de la pasta- en Pattanam, en la India (Járrega y Hereter, 2015). Por otro lado, creemos que es un indicio de la potente capacidad de producción que pudo tener el hipotético Lucius Minicius Natalis del s. I d. C., con la capacidad de exportar vino a Carthago y a Oriente. Esta pudo ser la base de la riqueza que dio lugar a que dos generaciones más tarde los miembros de su familia pudiesen acceder a la dignidad senatorial e incluso al consulado.

\section{Conclusiones}

Por todo lo antes expuesto proponemos, de forma hipotética, pero creemos que con bases verosímiles, que el sello anfórico $L \cdot M \cdot N$ pueda hacer referencia a los tria nomina Lucius Minicius Natalis, pudiendo ser un ancestro de los conocidos senadores de Barcino, posiblemente el abuelo de Minicius Natalis padre. Esta familia, que pudo haberse contado entre los fundadores de la colonia, podría haberse enriquecido mediante el negocio, tan lucrativo como especulativo, del vino, llegando a poder asumir los requisitos económicos necesarios para que uno de sus miembros llegara a convertirse en senador a finales del s. I o inicios del II d. C. Tal y como ya han señalado algunos autores la fortuna de los Minicii Natales procedía de sus negocios en Hispania (Laporte y Dupuis, 2009: 57). La existencia de un fundus Minicianus en Sant Joan Despí, situado en el Baix Llobregat y muy cerca del núcleo urbano de Barcino, así como el hallazgo del sello $M I N \cdot C E L$ en la misma localidad, permiten plantear esta hipótesis con una buena base. Si podemos asociar el sello $L \cdot M \cdot N$ a esta producción, su desarrollo en relación con un Lucius Minicius Natalis del s. I d. C. resultaría totalmente lógico, y nos permitiría documentar el origen familiar de los Minicii Natales de Barcino del s. II en la centuria anterior, y relacionarlos con la élite urbana que tenía posesiones agrícolas que rentabilizaban con la producción y exportación de vino.

\section{Bibliografía}

Abascal, J. M. (1994): Los nombres personales en las inscripciones latinas de Hispania. Murcia.

Abascal, J. M. (2016): “A propósito de la auto-representación epigráfica de las élites urbanas del Occidente romano". En Marco, F.; Pina, F. y Remesal, J. (eds.): Autorretratos. La creación de la imagen personal en la Antigüedad. Instrumenta, 53. Barcelona, pp. 175-185.

Alföldy, G. (1975): Die Römischen Inschrinften von Tarraco (= RIT), Madrider Forschungen, 10. Berlín: DAI.

Alföldy, G. (1996): "Der römische Bogen über der Via Augusta bei Tarraco (Arc de Berà) und seine Inschrift", Klio, 78, pp. 158-170.

Andreu, J.; Curulla, O. y Otiña, P. (2006): "Un nuevo documento sobre los Minicii de Tarraco", Butlletí Arqueologic, 28, pp. 199-210.

Andreu, J.; Curulla, O. y Otiña, P. (2008): "Los Minicii de Tarraco. En torno a un nuevo documento epigráfico tarraconense", Epigraphica. Periodico Internazionale di Epigrafia, Lxx, pp. 103-117.

Bergé, A. (1990): "Les marques sur amphores Pascual 1 de Port-la-Nautique", Cahiers d'Archeologie Subaquatique, 9, pp. 131-201.

Berni, P. (1996): "Instrumentum domesticum romà del Museu Episcopal de Vic. La col-lecció de segells en àmfora, tegula i morter", Pyrenae, 27, pp. 311-326.

Berni, P. (2010): "Epigrafia sobre amphorae, tegulae, imbrex i dolia a l'àrea occidental del Camp de Tarragona”. En Gorostidi, D. (ed.): Ager Tarraconenis 3. Les inscripcions romanes. Documenta, 16. Tarragona: ICAC, pp. 153-210.

Berni, P. (2015): "Novedades de epigrafía anfórica en el Baix Llobregat”. En Martínez Ferreras, V. (ed.): La difusión comercial de las ánforas vinarias de Hispania Citerior - Tarraconensis (s. I a. C. - I d. C.). Oxford, pp. 55-66.

Berni, P. y Carreras, C. (2013): "Corpus epigràfic de segells en àmfores, dolia, tegulae i gerres de cerámica comuna oxidada del Baix Llobregat”. En Carreras, C.; López, A. y Guitart, J. (eds.): Barcino II. Marques i terrisseries d'àmfores al Baix Llobregat. Barcelona: Institut d'Estudis Catalans, pp. 127-285.

Berni, P.; Carreras, C. y Olesti, O. (2005): "La gens Licinia y el Nordeste peninsular. Una aproximación al estudio de las formas de propiedad y de gestión de un rico patrimonio familiar", Archivo Español de Arqueología, 78, pp. 167-187. 
Berni, P. y Miró, J. (2013): “Dinámica socioeconómica en la Tarraconense Oriental a finales de la República y comienzos del Imperio. El comercio del vino a través de la epigrafía anfórica”. En López Vilar, J. (ed.): Tarraco Biennal: Govern i societat a la Hispània romana. Novetats epigràfiques. Homenatge a $G$. Alföldy. Tarragona, pp. 63-83.

Bouscaras, A. (1974): "Les marques sur amphores de Port la Nautique", Cahiers d'Archeologie Subaquatique, 3, pp. 103-131.

Caballos, A. (1995): "Los magistrados de orden senatorio originarios de Hispania en las provincias norteafricanas durante el Alto Imperio Romano”. En Ripoll, E. y Ladero, M. (eds.): Actas II Congreso Internacional 'El Estrecho de Gibraltar'. Madrid: UNED, vol. 2, pp. 211-248.

Cabrelles, I. (2013): "Elits ciutadanes i propietat rural durant l'Alt Imperi. El cas dels Clodii de Tarraco", Pyrenae, 44 (2), pp. 7-32.

Carreras, C.; Folch, J. y Guitart, J. (eds.) (2019): Laietània interior: marques $i$ terrisseries d'àmfores al Vallès Occidental i Oriental. Barcelona.

Carreras, C. y Guitart, J. (eds.) (2009): Barcino I: Marques $i$ terrisseries d'àmfores al pla de Barcelona. Barcelona.

Carreras, C.; López Mullor, A. y Guitart, J. (eds.) (2013): Barcino II: Marques i terrisseries d'àmfores del Baix Llobregat. Barcelona.

Christol, M. y Plana, R. (1997): "Els negotiatores de Narbona i el vi català", Faventia, 19 (2), pp. 75-95.

Christol, M. y Plana, R. (1998): “De la Catalogne à Narbonne: épigraphie amphorique et épigraphie lapidaire. Les affaires de Veiento". En PAcI, G. (ed.): Actes $I X^{e}$ Rencontre franco-italienne sur l'épigraphie $d u$ monde romain. Macerata: Univ. degli Studi di Macerata, pp. 273-302.

$\mathrm{CIL}=$ Corpus Inscriptionum Latinarum.

Colom, E. y Járrega, R. (2020): "Les àmfores tarraconenses de procedencia subaquàtica de Porto Cristo (Manacor, Mallorca)". En Hernández-Gasch, J.; Rivas Antequera, M. y Rivas Llompart, M. (coords.): VIII Jornades d'Arqueologia de les Illes Balears. Palma de Mallorca: Consell Insular de Mallorca, pp. 277-287.

Comas, M. (1997): Baetulo. Es marues d'àmfora. Corpus International des Timbres Amphoriques, 2. Barcelona.

Cortadella, J. (2006): "Los negocios de Lucius Minicius Natalis en el limes africano". En War and Territory in the Roman World. BAR. Oxford, pp. 205-211.
Daura, A. y Puigví, V. (1982): "El jaciment arqueològic del Cap del Pont del Gurri (Osona)”, Ausa, 10, pp. 83-93.

Delattre, A. L. (1906): "Un second mur à amphores de la colline Saint-Louis à Carthage", Bulletin Archeologique de Sousse, 4, pp. 33-48.

Dupré, X. (1994): L'Arc romà de Berà. Barcelona.

Eck, W. y Navarro, F. J. (1998): “Das Ehremonument der colonia Carthago für L. Minicius Natalis Quadronius Verus in seiner Heimatstadt Barcino", Zeitschrift für Papyrologie und Epigraphik, 123, pp. 237-248.

Erkelenz, D. (1998): "Ehrenmonumente des L. Minicius Natalis in Rom und Africa", Zeitschrift für Papyrologie und Epigraphik 123, pp. 257-269.

Estrada, J. (1998): "L'Itinerari dels Vasos Apol-linars en el trajecte de Granollers a Tarragona”. En MAYer, M.; Nolla, J. M. y PARdo, J. (eds.): De les estructures indigenes a l'organització provincial de la Hispania Citerior. Barcelona, pp. 201-220.

Fabre, G.; Mayer, M. y RodÀ, I. (1983): Inscripcions romanes de Mataró i de la seva área. Mataró.

Fabre, G.; Mayer, M. y RodÀ, I. (1984): Inscriptions romaines de Catalogne, I. Barcelona (sauf Barcino) (= IRC I). París.

Fabre, G.; Mayer, M. y RodÀ, I. (1997): Inscriptions romaines de Catalogne, IV. Barcino (= IRC IV). París.

FHA = Cf. Grosse, R. (1959): Fontes Hispaniae Antiquae.

Freed, J. (1998): "Stamped Tarraconensian Dressel 2-4 amphoras at Carthage". En Comas, M. y Padrós, P. (coords.): II Col.loqui Internacional d'Arqueologia Romana. El Vi a l'Antiguitat. Economia, producción $i$ comerç al Mediterrani occidental. Monografies Badalonines, 14. Badalona: Museu de Badalona, pp. 350-356.

Grosse, R. (1959): Fontes Hispaniae Antiquae. Barcelona, vol. VII.

Guasch, D.; Menéndez, X. y Solias, J. M. (1996): “Aproximació a l'estudi del poblament d'època romana a la vall de Verç (entorn de Sant Just Desvern, Baix Llobregat)", Miscel-lània Santjustenca, 7, pp. 9-64.

IRC = Cf. FABre, G.; MAYer, M. y RodÀ, I.: Inscriptions romaines de Catalogne.

JÁrRegA, R. (2015): “Ánforas vinarias en el este de la Hispania Citerior en época tardorrepublicana (siglo I a. C.): epigrafía anfórica y organización de la producción”, Spal, 24, pp. 77-98.

JÁrrega, R. (2016a): "Personajes foráneos en la epigrafía de las ánforas Pascual 1 y Oberaden 74. Aproximación a los cambios en la gestión de la producción 
vinaria en la Hispania Citerior en época de Augusto", Dialogues d'Histoire Ancienne, 42 (2), pp. 155-190.

JÁrRega, R. (2016b): “Los nomina en las marcas de ánforas de las formas Pascual 1 y Oberaden 74. Contribución al estudio de la producción de ánforas vinarias en el noreste de la Hispania Citerior en época de Augusto", Revista d'Arqueologia de Ponent, 26, pp. 73-93.

JÁRregA, R. (2017): “Una nueva y atípica marca en un ánfora de la forma Oberaden 74, hallada en la villa romana de La Llosa (Cambrils, Tarragona)", Boletín SECAH-Ex Officina Hispana, 8, pp. 59-61.

JÁrRega, R. (2018): "Los nomina en la epigrafía anfórica de las ánforas Dressel 2-4 del NE de la Hispania Citerior. Cambios estructurales e implicación de las élites urbanas", Saguntum, 50, pp. 175-202.

Járrega, R. y Berni, P. (2013): "El taller de ánforas de Malgrat de Mar (Barcelona): arqueometría y epigrafía”. En Morais, R.; Fernández, M. J. y Sousa, M. J. (eds.): As produçōes cerâmicas de imitaçāo na Hispania. Monografías Ex Officina Hispana, 2. Porto: Univ. do Porto- SECAH, pp. 393-403.

Járrega, R. y Hereter, R. (2015): “Un fragmento de ánfora romana de la forma Dressel 2-4 de procedencia layetana hallado en la India (Pattanam, estado de Kerala)", Boletin SECAH-Ex Officina Hispana, 6, pp. 36-37.

Járrega, R. y Prevosti, M. (2011): "Figlinae tarraconenses. La producció ceràmica a l'ager Tarraconensis". En Prevosti, M. y Martín, A. (eds.): Ager Tarraconensis 2. El poblament. Tarragona, pp. 455-489.

Laporte, J. P. y Dupuis, X. (2009): “De Nigrenses Maiores à Négrine”, Antiquités Africaines, 45, pp. 51-102.

López Mullor, A. (1989): "Ceramiques romanes de parets fines del Museu Episcopal de Vic", Studia Vicensia, 17, pp. 9-33.

López Mullor, A. (2009): "Els centres productors d'àmfores de Sant Boi de Llobregat i Darró (Vilanova i la Geltrú)". En Prevosti, M. y Martín, A. (eds.): El vi tarraconense i laietà: ahir i avui. Actes del simpòsium. Documenta, 7. Tarragona, pp. 61-98.

López Mullor, A. y Martín Menéndez, A. (2008a): "Tipologia i datación de les àmfores tarraconenses produïdes a Catalunya". En López Mullor, A. y AquiluÉ, X. (eds.): La producción i el comerç de les àmfores de la Provincia Hispania Tarraconensis. Homenatge a R. Pascual i Guasch. Barcelona, pp. 33-94.

López Mullor, A. y Martín Menéndez, A. (2008b): "Las ánforas de la Tarraconense". En Bernal, D. y
Ribera, A. (eds.): Cerámicas hispanorromanas. Un estado de la cuestión. Cádiz: Univ. de Cádiz, pp. 689724.

Mayer, M. (1996): Gal.la Placídia i la Barcelona del s. v. Barcelona: Real Academia de Bones Lletres.

Mayer, M. (2015): “¿Propiedades de los Minicii Natales de Barcino en África?”. En Ruggeri, P. (ed.): L'Africa romana. Momenti i continuità e rottura: bilancio di trent'anni di convegni L'Africa Romana. Roma: Carocci Editore, pp. 1511-1520.

Medeksza, S.; Czerner, R.; Krawczyk-Szczerbinska, M.; Grzegorek, W.; BaKowska, G.; Zambrzycki, P.; Osiak, W.; Mrozek-Wysocka, M. y MajcheREK, G. (2008): "Marina El-Alamein: Conservation and restoration work in 2006", Polish Archaeology in the Mediterranean, 18, pp. 69-82.

Menéndez, F. X. y Solias, J. M. (1996): “La romanització del territori meridional de la colònia Barcino. El cas de la vall de la riera de Sant Just Desvern (Baix Llobregat)", Annals de l'Institut d'Estudis Gironins, 37, pp. 755-782.

Miró, J. (1985): "Les fonts escrites i el vi del Conventus Tarraconensis", Pyrenae, 21, pp. 105-112.

Miró, J. (1988a): "Les estampilles sobre àmfores catalanes. Una aportació al coneixement del comerç del vi del Conventus Tarraconensis a finals de la República i principis de l'Imperi". En MAYer, M. y RodÀ, R. (eds.): Epigrafia. Fonaments, 7. Barcelona, pp. 243263.

Miró, J. (1988b): La producción de ánforas romanas en Catalunya. Un estudio sobre el comercio del vino de la Tarraconense (siglos I a.C.- I d.C.). BAR Intern. Ser, 473. Oxford: Archaeopress.

Olesti, O. (2005): "Propiedad de la tierra y élites locales. El ejemplo del ager barcinonensis". En GARRIdo-Hory, M. y Gonzales, A. (eds.): Histoire, espaces et marges de l'Antiquité: hommages à Monique Clavel-Lévêque. Besançon, vol. 4, pp. 175-200.

Olesti, O. (2008): "Formas de propiedad y gestión de la tierra en la colonia de Barcino: una aproximación metodológica". En Mangas, J. y Novillo, M. A. (eds.): El territorio de las ciudades romanas. Madrid: Sísifo, pp. 279-308.

Olesti, O. y Carreras, C. (2013): "Le paysage social de la production vitivinicole dans l'ager Barcinonensis: esclaves, affranchis et institores", Dialogues d'Histoire Ancienne, 39 (2), pp. 147-189.

Pascual, R. (1991): Index d'estampilles sobre àmfores catalanes. Cuadernos de Arqueología, 5. Barcelona: L'Estaquirot.

Revilla, V. (1995): Producción cerámica, viticultura y propiedad rural en Hispania Tarraconensis (siglos I a. C.-III d. C.). Barcelona. 
Revilla, V. (2002): "El vi de Tàrraco durant el principal: elits urbanes i imatges de la producción", Citerior: Arqueologia i ciències de l'Antiguitat, 3, pp. 173-207.

Revilla, V. (2004): “Ánforas y epigrafía anfórica en Hispania Tarraconensis". En Remesal, J. (ed.): Epigrafía anfórica. Barcelona: Univ. de Barcelona, pp. 159-196.

RIT $=C f$. AlFöLDY, G. (1975).

RodÀ, I. (1978): "Le inscrizioni in onore di Lucius Minicius Natalis Quadronius Verus", Dacia, 22, pp. 219223.

RodÀ, I. (1988): "Luci Minici Natal Quadroni Ver i la societat barcelonina del seu temps", Revista de Catalunya, 22, pp. 37-51.

RodÀ, I. (2010): "La promoción de las elites en las ciudades del Conventus Tarraconensis". En Navarro, F. J. (ed.): Pluralidad e integración en el mundo romano. Col. Mundo Antiguo, 13. Barañáin, pp. 177-188.

Syme, R. (1981): "Rival Cities, Notably Tarraco and Barcino”, Ktema, vi, pp. 271-285.

Syme, R. (1982-83): "Spaniards at Tivoli", Ancient Society, XIII/XIV, pp. 241-263.

Tchernia, A. (1971): "Les amphores vinaires de Tarraconaise et leur exportation au début de l'Empire", Archivo Español de Arqueología, 44, pp. 38-85.
Tchernia, A. y Zevi, F. (1972): "Amphores vinaires de Campanie et de Tarraconaise à Ostie”. En Baldacci, P.; Kapitän, G.; Lamboglia, E.; Panella, C.; Rodríguez Almeida, E.; Sciarra, B. y Tchernia, A. (eds.): Recherches sur les amphores romaines. Colloque sur l'utilisation en histoire économique des données fournies par les amphores romaines. Collection de l'École Française de Rome, 10. Roma, pp. 35-67.

Tremoleda, J. (2000): Industria y artesanado cerámico de época romana en el nordeste de Catalunya (época augústea y altoimperial). BAR Intern. Ser., 835. Oxford: Archaeopress.

TremoledA, J. (2008): "Les instal-lacions productives d'àmfores tarraconenses". En López Mullor, A. y Aquilué, X. (coords.): La producció i el comer de les àmfores de la Provincia Hispania Tarraconensis. Homenatge a R. Pascual i Guasch. Barcelona, pp. 113-150.

Tremoleda, J. (2016): “Caius Iulius Laetus, un productor d'Ermedàs i seu el mercat”. En Tremoleda, J. (coord.): El territori de Besalú abans del comtat. Quaderns de les Assemblees d'Estudis, 2. Besalú, pp. 155-163.

Verrié, F. P. (1989): "La inscripció olímpica del barcinonense Lucius Minicius Natalis Quadronius Verus", Espacio, Tiempo y Forma. Serie I. Prehistoria y Arqueología, 2, pp. 304-305. 